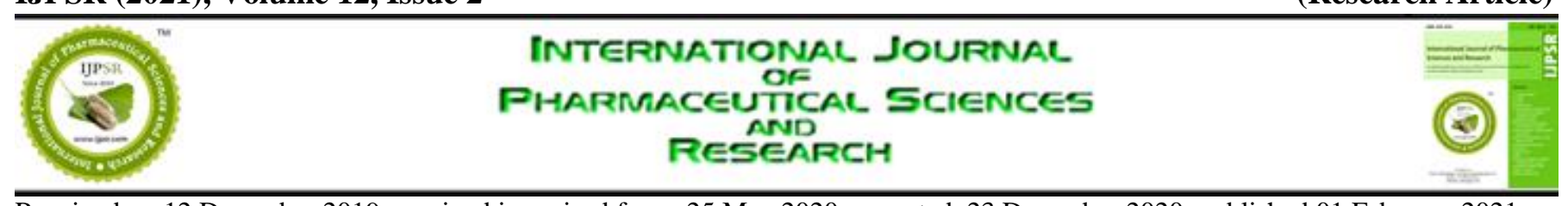

Received on 12 December 2019; received in revised form, 25 May 2020; accepted, 23 December 2020; published 01 February 2021

\title{
DEVELOPMENT AND VALIDATION OF DERIVATIVE UV SPECTROPHOTOMETRIC METHOD FOR DETERMINATION OF DULOXETINE
}

\author{
Lipsa Samal ${ }^{*}$, Laxmidhar Biswal ${ }^{2}$ and Prachi Rani Sahu ${ }^{1}$
}

Centurion University of Technology and Management ${ }^{1}$, R. Sitapur - 761211, Odisha, India. Macleods Pharmaceuticals Ltd ${ }^{2}$, Gangtok - 737135, Sikkim, India.

Keywords:

Duloxetine, UV Spectrophotometric method, derivative spectroscopy, Method validation, ICH guidelines

\section{Correspondence to Author:}

\section{Lipsa Samal}

Assistant Professor,

SPLS, Centurion University of

Technology and Management, R.

Sitapur - 761211, Odisha, India.

E-mail: lipsasama190@gmail.com

\begin{abstract}
Development and validation of a simple UV spectroscopic method for the determination of Duloxetine by the derivative spectrophotometric method is the objective of the present work. The analysis was carried out by using Shimadzu UV-1700, and Shimadzu UV-1800 UV spectrophotometer, and Acetonitrile and water (8:2) was used as solvent or mobile phase. Detection or qualitative analysis was carried out at a wavelength of $240 \mathrm{~nm}$. ICH guidelines were followed to verify the method validation process by using various parameters like linearity, accuracy, precision (interday and intraday), ruggedness, robustness, the limit of detection (LOD), and limit of quantification (LOQ). According to Beer's Lambert's law, the derivative UV spectrophotometric method was found linear in the range of $10-50 \mu \mathrm{g} / \mathrm{ml}$. The analytical method was rugged and robust with a $\%$ relative standard deviation of less than 1.8 . The percentage recoveries were higher than $98.7 \%$ in all the validation parameters and conditions. Based upon the analytical experiment, the developed method was found accurate, precise and rapid, and suitable for the rapid determination of Duloxetine for routine analysis.
\end{abstract}

INTRODUCTION: Chemically Duloxetine (Cymbalta) is methyl (3S) - 3 - (naphthalene - 1 yloxy) - 3 - (thiophen - 2 - yl) propyl] amine hydrochloride belongs to the class of antidepressant drugs. The Molecular formula, molecular mass, and molecular weight are $\mathrm{C}_{18} \mathrm{H}_{19} \mathrm{NOS}, 297.41456$ $\mathrm{g} / \mathrm{mol}$, and 333.88, respectively ${ }^{1,2,3,9}$. Route of administration is oral and is available as a tablet, capsule, and enteric-coated pellet dosage forms in the market ${ }^{3,9}$. It is freely soluble in water and soluble in methanol, DMSO, acetonitrile, and the storage temperatures is $25-30^{\circ} \mathrm{C}^{2,3,9}$.

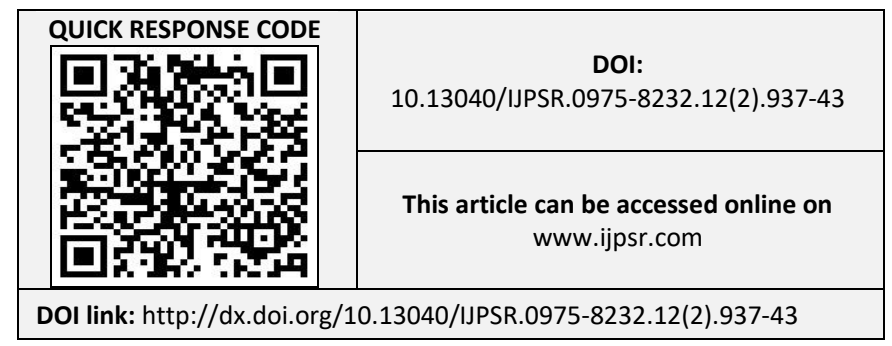

In the brain, Duloxetine inhibits the reuptake of both serotonin and nor-epinephrine (NE). Duloxetine increases dopamine (DA) level especially in the prefrontal cortex region so allowing greater diffusion of DA in this brain region ${ }^{4}$, where there are few DA reuptake pumps act by the inhibition of NE reuptake pumps (NET), which is believed to mediate reuptake of DA and $\mathrm{NE}^{5,6,9}$. The drug has no significant affinity for dopaminergic, cholinergic, histaminergic, opioid, glutamate, and GABA reuptake transporters.

Duloxetine undergoes hepatic metabolism by using two cytochrome $\mathrm{P}_{450}$ isoenzymes, and the metabolites are eliminated via urine 6, 7,9 . Derivative spectroscopy uses absorbance of $1^{\text {st }}$ or higher derivatives with respect to wavelength for both qualitative and quantitative analysis. In the year 1950, the concept of derivative spectroscopy was $1^{\text {st }}$ introduced. 
Due to the complexity of generating derivative spectra using early UV-Visible spectrophotometers and the baseline shift, the UV-spectroscopic method undergoes extensive modification. The problem arises either from the instrument, i.e., lamp or detector instabilities or sample handling. Using the derivative spectroscopy, the above problem can be eliminated as the $1^{\text {st }}$ derivative of a constant absorbance offset is zero and it always eliminates the baseline shifts and improves the accuracy and precision of the method. Derivative UV- spectrophotometry is an instrumental analytical technique that uses normal zero-order spectra of sample mathematically differentiated into derivative spectra $\left(1^{\text {st }}\right.$ or higher-order derivatives) ${ }^{10,11,12}$. Derivative spectrophotometric has found a wide range of application in both qualitative and quantitative chemical analysis i.e.

Macro to Nano Spectroscopy.

Multicomponent analysis.

$\checkmark$ Determination of one analyte in presence of matrix or for simultaneous assaying of few analytes.

$\checkmark$ Calculation of some physico-chemical constants, e.g. reaction, complexation or binding constants.

$\checkmark$ Application for investigation of some processes kinetics $^{10,11,12}$.

The present paper deals with the method development and validation of a derivative Spectrophotometric method for the determination of Duloxetine in pure powder form. The solubility of the drug was determined using various solvents and found that Duloxetine is freely soluble in Acetonitrile and water. So the analysis was performed using Acetonitrile and water to optimize the Analytical method development and validation.

\section{MATERIALS AND METHODS:}

Instrumentation: The experiment was carried out from December 2019 to March 2020 at Centurion University of Technology and Management, Jatni, Odisha, India using Shimadzu UV-1800 and Shimadzu UV-1700 spectrophotometer (single beam detector).

Chemicals and Reagents: Acetonitrile was Purchased From Thomas Beaker Chemicals Pvt.
Ltd., Mumbai, and double-distilled water was prepared in our college laboratory and used in the current study.

Preparation of the Solvent System: The analysis solvent mixture was prepared by using water and Acetonitrile in the ratio of $2: 8 \mathrm{v} / \mathrm{v}$ and sonicating the solvent system.

Preparation of the Standard Solution: Powdered drug Duloxetine has accurately weighed up to 10 $\mathrm{mg}$ and taken in a $10 \mathrm{ml}$ volumetric flask, and the prepared solvent was added up to the mark, which gives the concentration of 1000 PPM. From the stock solution, different aliquots of the solution were prepared by taking $0.1,0.2,0.3,0.4,0.5 \mathrm{ml}$ of solution in every $10 \mathrm{ml}$ of volumetric flask separately, and it was made up to mark with the same solvent to produce 10, 20, 30, 40, 50 PPM, respectively.

Calibration Curve: $1^{\text {st }}$ the baseline was obtained by taking only the prepared solvent, which is considered a blank reading. Then the prepared stock solution was scanned in the UV- spectroscopy with the prepared solvent to construct Beer's law plot for the pure drug. By extrapolation of the curve and by using the software, the absorption maximum was found at $290 \mathrm{~nm}$. The absorbance of each solution was measured at their respective $\lambda_{\max }$ against water: Acetonitrile (20:80) as blank. Finally, the calibration curve was plotted by taking the concentration of the drug on the $\mathrm{x}$-axis and absorbance on the y-axis.

Method Validation: Method validation is a documented process used to assure that the analytical test used for a specific test is suitable for the intended use. It is a critical element ensuring the quality and safety of the analytical product.

Accuracy: 8, 9 To determine the accuracy of the proposed method, different sample solutions of the same concentration 30 PPM were analyzed to determine $\%$ recovery of Duloxetine by the standard addition recovery method. The study was carried out by preparing the 5 set of solutions each having a concentration of 10, 20, 30, 40, 50 PPM. From this, the concentration of 30 PPM was selected, and the absorbance was noted down for the set of 5 reading. Then the mean, standard deviation (SD) and \% relative standard deviation 
(RSD) were calculated. The results were shown in Table 3.

Precision: 8, 9 The precision of the proposed method was assessed by intra-day and inter-day variation studies using only one concentration of Duloxetine (30 ppm) for several times. The intraday study was carried out by preparing the 5 set of solutions each having the concentration of 10, 20, 30, 40, 50 PPM. From this, the concentration of 30 PPM was selected, and the absorbance was noted down for the set of 5 reading and was analyzed on the same day, whereas inter-day study was carried out by the same process but by analyzing five sample solutions of each concentration for 5 repeated days. Then the mean, standard deviation (SD) and \% relative standard deviation (RSD) were calculated. The results were shown in Tables 4 and 5.

\section{Limit of Detection (LOD) and Limit of Quanti- fication (LOQ): ${ }^{9,10,11}$}

LOD: The detection limit of an individual analytical procedure is the lowest amount of analyte in a sample, which can be detected but not necessarily quantified as an exact value. The detection limit is determined by the analysis of samples with known concentrations of analyte and by establishing the minimum level at which the analyte can be reliably detected.

LOQ: The quantification limit of an individual analytical procedure is the lowest amount of analyte in a sample, which can be quantitatively determined with suitable precision and accuracy. It is a parameter of quantitative assays for low levels of compounds in the sample and is particularly used for the determination of impurities and/or degradation products.

$$
\begin{aligned}
& \mathrm{LOD}=3.3 \sigma / \mathrm{S} \\
& \mathrm{LOQ}=10 \sigma / \mathrm{S}
\end{aligned}
$$

Where, $\sigma=$ standard deviation of the regression line $\mathrm{S}=$ slope of the calibration curve.

Robustness: ${ }^{\mathbf{8 , 9 , 1 0}}$ To determine the robustness of any analytical method, three experimental parameters such as the composition of the mobile phase, detection wavelength, and flow rate were slightly altered. In this study, the composition of the mobile phase is changed to get the result. Then the mean, standard deviation (SD), and \% relative standard deviation (RSD) were calculated. The results were shown in Tables 8 and 9.

Ruggedness: ${ }^{9,10}$ To determine method ruggedness the study was carried out by changing the different models of UV spectrophotometer. Then the mean, standard deviation (SD), and \% relative standard deviation (RSD) were calculated. The results were shown in Tables 6 and 7.

RESULTS AND DISCUSSION: The proposed method for normal determination of Duloxetine hydrochloride showed molar absorptivity of 2.995 $\times 10^{-7} \mathrm{~L} / \mathrm{mol} . \mathrm{cm}$. Linear regression of absorbance on concentration gave the equation $\mathrm{y}=0.020 \mathrm{x}+$ 0.007 with a correlation coefficient (r) of 0.999 . The optical characteristics such as Beer's law limit, Sandell's sensitivity, Standard deviation, \% RSD, LOD, LOQ were calculated and are given in Table 10.

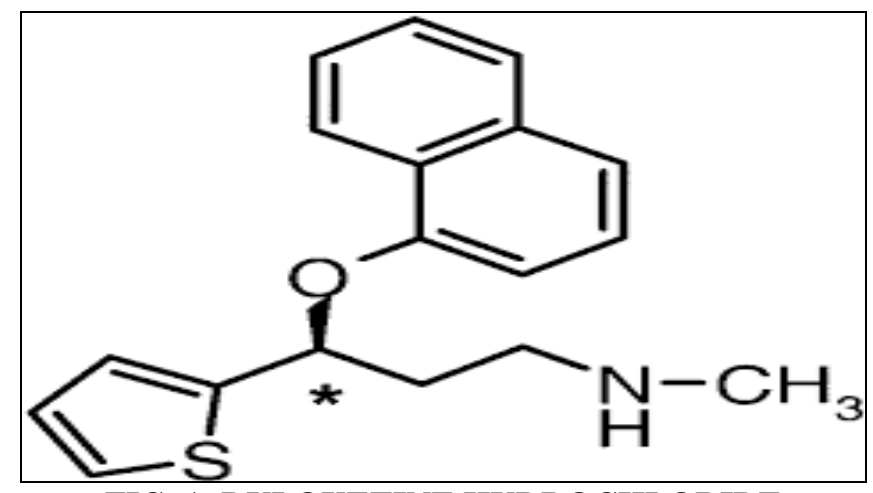

FIG. 1: DULOXETINE HYDROCHLORIDE

The derivative spectroscopy method showed molar absorptivity of $4.901 \times 10^{-7} \mathrm{~L} / \mathrm{mol} . \mathrm{cm}$. Linear regression of absorbance on concentration gave the equation $\mathrm{y}=-0.004 \mathrm{x}-0.007$ with a correlation coefficient (r) of 0.996. The optical characteristics such as Beer's law limit, Sandell's sensitivity, Standard deviation, \% RSD, LOD, LOQ were calculated and given in Table 11.

By comparing the UV-spectroscopic method and derivative UV-spectroscopic method for Duloxetine, the UV-spectroscopic method was found to be more accurate than the derivative method. Still, the derivative UV-spectroscopic method was found to be precise and can also be used in routine analysis, and in the future further, analysis of higher-order spectroscopy can be done to produce a more accurate result. 


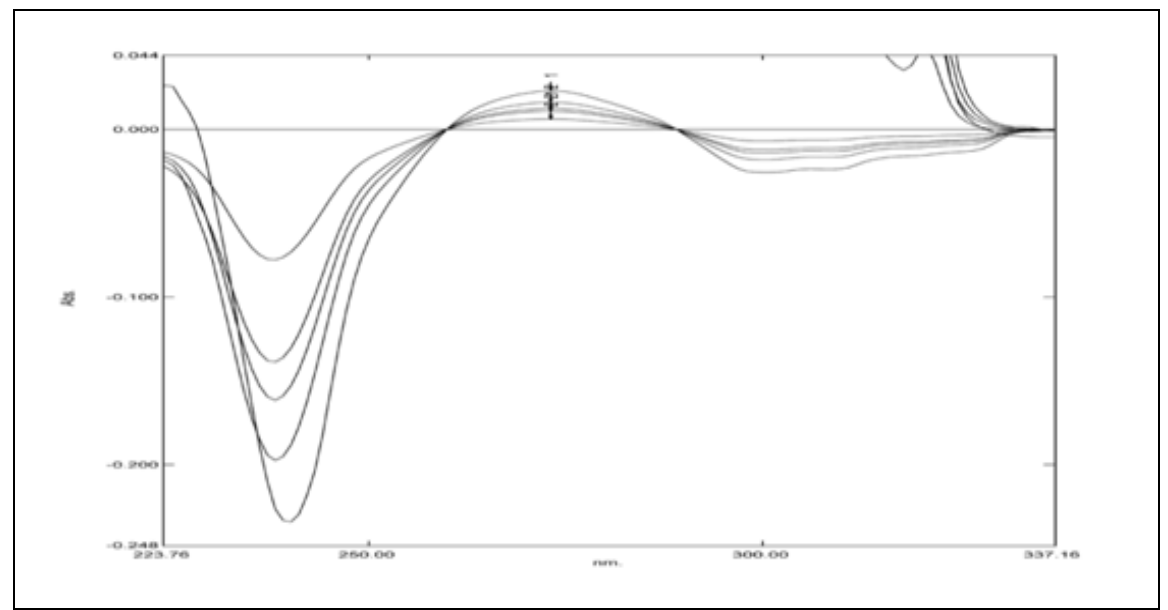

FIG. 2: OVERLAY SPECTRA OF DULOXETINE BY UV-VISIBLE SPECTROSCOPY USING WATER: ACETONITRILE (2:8). This spectra showing $\chi \max$ (maximum wavelength) is about $290 \mathrm{~nm}$.

TABLE 1: CALIBRATION TABLE OF UV-VIS SPECTROPHOTOMETRIC METHOD FOR DULOXETINE

\begin{tabular}{cccccccccc}
\hline Conc. & Abs. 1 & Abs. 2 & Abs. 3 & Abs. 4 & Abs. 5 & Abs. 6 & Mean & SD & \% RSD \\
\hline 10 & 0.21 & 0.213 & 0.212 & 0.214 & 0.206 & 0.202 & 0.2095 & 0.004637 & 2.213274 \\
20 & 0.412 & 0.423 & 0.414 & 0.412 & 0.411 & 0.415 & 0.4145 & 0.004416 & 1.065351 \\
30 & 0.611 & 0.602 & 0.601 & 0.603 & 0.618 & 0.621 & 0.609333 & 0.008687 & 1.425682 \\
40 & 0.819 & 0.822 & 0.827 & 0.819 & 0.816 & 0.824 & 0.821167 & 0.003971 & 0.483547 \\
50 & 1.023 & 1.019 & 1.014 & 1.018 & 1.016 & 1.015 & 1.0175 & 0.003271 & 0.321483 \\
& & & & & & & 0.6144 & 0.004996 & 1.101867 \\
\hline
\end{tabular}

A calibration curve was plotted using the concentration on $\mathrm{X}$-axis and mean absorbance on $\mathrm{Y}$-axis

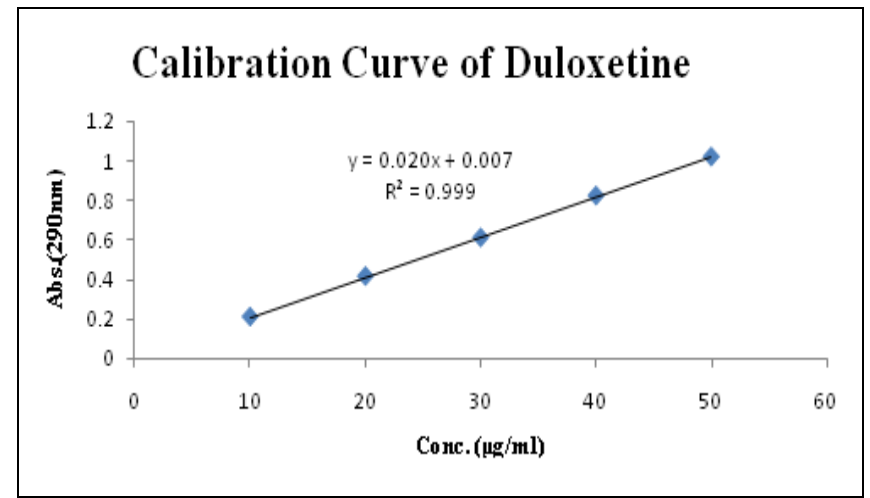

FIG. 3: CALIBRATION CURVE OF DULOXETINE IN NORMAL UV- SPECTROSCOPY. From the calibration curve it was found that it shows linearity in the range of $10-50 \mu \mathrm{g} / \mathrm{ml}$ with regression coefficient 0.9999

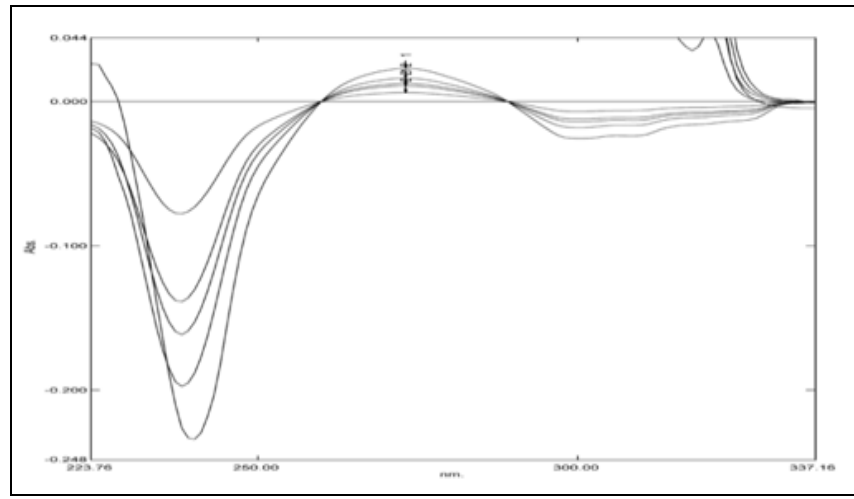

FIG. 4: OVERLAY 1ST DERIVATIVE SPECTRA OF DULOXETINE AT 240 nm USING WATER: ACETONITRILE (2:8)

TABLE 2: CALIBRATION TABLE FOR ${ }^{\text {ST }}$ DERIVATIVE UV-VIS SPECTRO-PHOTOMETRIC METHOD FOR DULOXETINE

\begin{tabular}{cccccccccc}
\hline Conc. & Abs. 1 & Abs. 2 & Abs. 3 & Abs. 4 & Abs. 5 & Abs. 6 & Mean & SD & \% RSD \\
\hline 10 & -0.058 & -0.057 & -0.059 & -0.057 & -0.059 & -0.058 & -0.058 & 0.000894 & -1.54 \\
20 & -0.109 & -0.108 & -0.109 & -0.108 & -0.109 & -0.108 & -0.1085 & 0.000548 & -0.51 \\
30 & -0.147 & -0.148 & -0.146 & -0.147 & -0.146 & -0.149 & -0.1471 & 0.001169 & -0.79 \\
40 & -0.201 & -0.202 & -0.202 & -0.201 & -0.201 & -0.203 & -0.2016 & 0.000816 & -0.404 \\
50 & -0.256 & -0.255 & -0.254 & -0.256 & -0.258 & -0.257 & -0.256 & 0.001414 & -0.55 \\
\hline
\end{tabular}

A calibration curve was plotted using the concentration on $\mathrm{X}$-axis and mean absorbance on Y-axis.

TABLE 3: ACCURACY DATA OF THE $1^{\text {ST }}$ DERIVATIVE UV-VIS SPECTROPHOTOMETRIC METHOD FOR DULOXETINE

\begin{tabular}{ccccc}
\hline S. no. & Concentration $(\boldsymbol{\mu g} / \mathbf{m l})$ & Absorbance & Calculated Amount & Statistical Analysis \\
\hline 1 & 30 & -0.132 & 31.25 & Mean=30.25 \\
2 & 30 & -0.128 & 30.25 & SD $=0.57$ \\
3 & 30 & -0.126 & 29.75 & $\%$ RSD $=1.88$ \\
4 & 30 & -0.127 & 30 & \\
5 & 30 & -0.126 & 29.75 & \\
\hline
\end{tabular}


TABLE 4: INTER DAY PRECESSION DATA OF THE $1^{\text {ST }}$ DERIVATIVE UV-VIS DERIVATIVE SPECTROPHOTOMETRIC METHOD FOR DULOXETINE

\begin{tabular}{ccccccc}
\hline S. no. & Concentration $(\boldsymbol{\mu g} / \mathbf{m l})$ & Abs. 1 & Abs. 2 & Abs. 3 & Average & Statistical analysis \\
\hline 1 & 30 & -0.125 & -0.128 & -0.134 & -0.129 & Mean=-0.12713 \\
2 & 30 & -0.127 & -0.128 & -0.128 & -0.127 & Std. Dev. $=0.00126$ \\
3 & 30 & -0.126 & -0.126 & -0.126 & -0.126 & $\%$ RSD $=0.99149$ \\
4 & 30 & -0.127 & -0.127 & -0.127 & -0.127 & \\
5 & 30 & -0.126 & -0.126 & -0.126 & -0.126 & \\
\hline
\end{tabular}

TABLE 5: INTRA DAY PRECESSION DATA OF THE $1^{\mathrm{ST}}$ DERIVATIVE UV-VIS DERIVATIVE SPECTROPHOTOMETRIC METHOD FOR DULOXETINE

\begin{tabular}{ccccccc}
\hline S. no. & Conc. $(\boldsymbol{\mu g} / \mathbf{m l})$ & Day 1 & Day2 & Day 3 & Average & Statistical analysis \\
\hline 1 & 30 & -0.127 & -0.124 & -0.125 & -0.1253 & Mean $=-0.1262$ \\
2 & 30 & -0.128 & -0.128 & -0.127 & -0.1276 & Std. Dev. $=0.001121$ \\
3 & 30 & -0.129 & -0.125 & -0.124 & -0.126 & $\%$ RSD $=0.8878$ \\
4 & 30 & -0.128 & -0.127 & -0.126 & -0.127 & \\
5 & 30 & -0.125 & -0.126 & -0.124 & -0.125 & \\
\hline
\end{tabular}

TABLE 6: RUGGEDNESS DATA OF THE $1^{\text {ST }}$ DERIVATIVE UV-VIS SPECTROPHOTOMETRIC METHOD BY DIFFERENT ANALYST FOR DULOXETINE USING UV- 1700

\begin{tabular}{ccccc}
\hline S. no. & Conc. $(\boldsymbol{\mu g} / \mathbf{m l})$ & Abs. & Calc. Amt. & Statistical deviation \\
\hline 1 & 30 & -0.127 & 30 & Mean $=30.12$ \\
2 & 30 & -0.128 & 30.25 & Std. deviation $=0.46$ \\
3 & 30 & -0.126 & 29.75 & $\%$ RSD $=1.55$ \\
4 & 30 & -0.127 & 30 & \\
5 & 30 & -0.126 & 29.75 & \\
6 & 30 & -0.131 & 31 & \\
\hline
\end{tabular}

TABLE 7: RUGGEDNESS DATA OF THE $1^{\text {ST }}$ DERIVATIVE UV- VIS SPECTROPHOTOMETRIC METHOD BY DIFFERENT ANALYST FOR DULOXETINE USING UV- 1800

\begin{tabular}{ccccc}
\hline S. no. & Conc. $(\boldsymbol{\mu g} / \mathbf{m l})$ & Abs. & Calc. Amt. & Statistical Deviation \\
\hline 1 & 30 & -0.128 & 30.25 & Mean $=30.08$ \\
2 & 30 & -0.128 & 30.25 & Std. Deviation $=0.30$ \\
3 & 30 & -0.126 & 29.75 & $\%$ RSD $=1.006$ \\
4 & 30 & -0.127 & 30 & \\
\hline
\end{tabular}

TABLE 8: ROBUSTNESS DATA OF THE $1^{\text {ST }}$ ORDER DERIVATIVE UV-VIS SPECTROPHOTOMETRIC METHOD BY FOR DULOXETINE USING ACETONITRILE: WATER (78:22)

\begin{tabular}{ccccc}
\hline S. no. & Conc. $(\boldsymbol{\mu g} / \mathbf{m l})$ & Abs. & Calc. Amt. & Statistical Deviation \\
\hline 1 & 30 & -0.131 & 31 & Mean $=30.208$ \\
2 & 30 & -0.128 & 30.25 & Std.dev $=0.48$ \\
3 & 30 & -0.126 & 29.75 & $\%$ RSD $=1.606$ \\
4 & 30 & -0.127 & 30 & \\
5 & 30 & -0.126 & 29.75 & \\
6 & 30 & -0.129 & 30.5 & \\
\hline
\end{tabular}

TABLE 9: ROBUSTNESS DATA OF THE $1^{\text {ST }}$ ORDER DERIVATIVE UV-VIS SPECTROPHOTOMETRIC METHOD BY FOR DULOXETINE USING ACETONITRILE: WATER (82:18)

\begin{tabular}{ccccc}
\hline S. no. & Conc. $(\boldsymbol{\mu g} / \mathbf{m l})$ & Abs. & Calc. Amount & Statistical Deviation \\
\hline 1 & 30 & -0.127 & 29.85 & Mean $=30.35$ \\
2 & 30 & -0.128 & 30.1 & Std.dev $=0.52$ \\
3 & 30 & -0.129 & 30.35 & $\% \mathrm{RSD}=1.72$ \\
4 & 30 & -0.127 & 29.85 & \\
5 & 30 & -0.132 & 31.1 & \\
6 & 30 & -0.131 & 30.85 & \\
\hline
\end{tabular}


TABLE 10: OPTICAL CHARACTERISTICS OF DULOXETINE BY NORMAL UV-VISIBLE SPECTROSCOPIC METHOD

\begin{tabular}{cc}
\hline Beer's Law Limit $(\boldsymbol{\mu g} / \mathbf{m l})$ & $\mathbf{1 0 - 5 0} \boldsymbol{\mu g} / \mathbf{m l}$ \\
\hline$\chi_{\max }$ & $240 \mathrm{~nm}$ \\
Molar extinction co-efficient $(\mathrm{E} 1 \%)$ & 2036.66 \\
Molar absorptivity $\left(\mathrm{L} \mathrm{mole}^{-1} \mathrm{~cm}^{-1}\right)$ & $2.995 \times 10^{-7}$ \\
Sandell's sensitivity $\left(\mu \mathrm{g} \mathrm{cm}^{-2} /\right.$ & 0.540 \\
0.001 absorbance unit) & \\
Standard deviation & 0.004996 \\
\% Relative standard deviation & 1.101867 \\
\hline Confidence Limits & \\
\hline Correlation coefficient & 0.999 \\
Regression equation (Y) & $0.020 \mathrm{x}+0.007$ \\
Slope (a) & 0.020 \\
Intercept (b) & 0.007 \\
LOD & $0.4 \mu \mathrm{g} / \mathrm{ml}$ \\
LOQ & $1.32 \mu \mathrm{g} / \mathrm{ml}$ \\
\hline
\end{tabular}

TABLE 11: OPTICAL CHARACTERISTICS OF DULOXETINE BY UV- VISIBLE SPECTROSCOPIC METHOD BY $1^{\text {ST }}$ ORDER DERIVATIVE SPECTROSCOPIC METHOD

\begin{tabular}{cc}
\hline Beer's Law Limit $(\boldsymbol{\mu g} / \mathbf{m l})$ & $\mathbf{1 0 - 5 0} \boldsymbol{\mu g} / \mathbf{m l}$ \\
\hline$\chi_{\max }$ & $240 \mathrm{~nm}$ \\
Molar extinction co-efficient $(\mathrm{E} 1 \%)$ & 4900.01 \\
Molar absorptivity (L mole-1 $\left.\mathrm{cm}^{-1}\right)$ & $4.901 \times 10^{-7}$ \\
Sandell's sensitivity & 0.204 \\
$(\mu \mathrm{g} \mathrm{cm}-2$ / 0.001 absorbance unit) & \\
Standard deviation & 0.005996 \\
\% Relative standard deviation & 1.211867 \\
Confidence limits & \\
Correlation coefficient & 0.996 \\
Regression equation (Y) & $-0.004 \mathrm{x}-0.007$ \\
Slope (a) & -0.004 \\
Intercept (b) & 0.007 \\
LOD & $0.6 \mu \mathrm{g} / \mathrm{ml}$ \\
LOQ & $1.52 \mu \mathrm{g} / \mathrm{ml}$ \\
\hline
\end{tabular}

CONCLUSION: The proposed method UV- Vis Spectrophotometric method by 1 st order derivative spectroscopy was found to be simple, precise, and accurate and validated as per ICH guidelines and used for rapid estimation of Duloxetine. The mobile phase is simple to prepare, inexpensive solvent available all the time. Hence, this method can be easily and conveniently adapted for routine analysis of Duloxetine in quality control laboratories, and the method can also be extended for the routine assay of Duloxetine in various formulations.

ACKNOWLEDGEMENT: Authors are thankful to the Centurion University of Technology And Management, Odisha, India, for providing the facilities for carrying out this research work in the laboratories.
Authors Contributions: For preparing this research paper L. Samal and P. R. Sahu gave a substantial contribution by data collection, analysis, and interpretation by executing the experimental work in analysis laboratories. L. Biswal drafted the manuscript and extensively revised it to improve the quality of the manuscript. Conception, design, critical revision of the article, and supervision of the work has been done by L. Samal, L. Biswal \& P. R. Sahu.

CONFLICTS OF INTEREST: Authors declare that there is no conflict of interest.

\section{REFERENCES:}

1. Loyd V and Allen J: Remington- the science and practice of pharmacy. Pharmaceutical Press, Twenty Second Edition 2013.

2. Neil MJO: The Merck Index: an encyclopedia of chemicals, drugs, biological. Merck Research Laboratories, Fourteenth Edition 2006.

3. Lalit M: Drug Today. Current medical formulations, Two thousand seventeen Editions 2017.

4. Rang HP, Ritter JM and Flower RJ: Rang and Dale's pharmacology. Elsevier Churchill Livingstone publication, Eight Edition 2016.

5. Tripathy KD: Essentials of medical pharmacology. Jaypee brother's medical publishers (P) Ltd, Seven Edition 2013.

6. Skinner MH, Kuan HY, Pan A, Sathirakul K, Knadler MP and Gonzales CR: Duloxetine is both an inhibitor and a substrate of cytochrome P4502D6 in healthy volunteers. Clinical Pharmacology \& Therapeutics 2003; 73: 170-7.

7. Lantz RJ, Gillespie TA, Rash TJ, Kuo F, Skinner M and Kuan H: Metabolism, excretion and pharmacokinetics of duloxetine in healthy human subjects. Drug Metabolism and Disposition 2003; 31: 1142-50.

8. Bymaster FP, Beedle EE, Findlay J, Gallagher PT, Krushinski JH and Mitchell S: Duloxetine (Cymbalta), a dual inhibitor of serotonin and norepinephrine reuptake. Bioorganic \& Medicinal Chemistry Letters 2003; 13: 4477-80

9. Pursty A and Samal L: Development and validation of UV-VIS spectrophotometric method for determination of Duloxetine. International Journal of Pharmacy and Pharmaceutical Sciences 2019; 11(3): 27-31.

10. Anthony JO: Uses of Derivative Spectroscopy. Agilent Technologies, Innovating the HP Way, Publication Number 5963-3940E.URL https:// www.whoi. Edu/cms/ files/derivative_spectro-scopy_59633940_ 175744.pdf.

11. Bumbrah G and Sarin RK: Derivative Ultraviolet spectrophotometry: a rapid, screening tool for the detection of petroleum products residues in fire debris samples. Malaysian Journal of Forensic Sciences 2016; 7(1): 17-26.

12. Xiangping L, Yingxiang D and Xiulan W: Simple UV spectrophotometric determination of duloxetine hydrochloride in bulk and in pharmaceutical formulations. Spectrochimica Acta Part A 2008; 71: 915-20.

13. Prabhu SL, Shahnawaz S, Dinesh Kumar $C$ and Shirwaikar: Spectrofluorimetric method for determination of Duloxetine hydrochloride in bulk and pharmaceutical dosage forms. Indian Journal of Pharmaceutical Sciences 2008; 70: 502-3. 
14. Yunoos M, Sankar DG, Kumar BP and Hameed S: Simple UV spectrophotometric determination of duloxetine hydrochloride in bulk and in pharmaceutical. European $\mathbf{J}$ of Medicinal Chemistry 2010; 7: 785-8.

15. Sydabi $P$, Muneer $S$, Ishaq BM and Kumar ES: Development and validation of an analytical method for duloxetine hydrochloride in capsule formulations by
HPLC-UV. Indo American Journal of Pharmaceutical Sciences 2014; 1: 11-6.

16. Methuku K, Aarelly K and Raghunandan N: Simple UV spectrophotometric determination of duloxetine hydrochloride in bulk and in pharmaceutical formulations. Journal of Pharmaceutical and Scientific Innovation 2012; 1: 81-6.

How to cite this article:

Samal L, Biswal L and Sahu PR: Development and validation of derivative UV-spectrophotometric method for determination of duloxetine. Int J Pharm Sci \& Res 2021; 12(2): 937-43. doi: 10.13040/IJPSR.0975-8232.12(2).937-43.

All $\odot 2013$ are reserved by the International Journal of Pharmaceutical Sciences and Research. This Journal licensed under a Creative Commons Attribution-NonCommercial-ShareAlike 3.0 Unported License

This article can be downloaded to Android OS based mobile. Scan QR Code using Code/Bar Scanner from your mobile. (Scanners are available on Google Playstore) 